\title{
Monitoring of Rain-Induced Landslides for the Territory Protection: The AD-VITAM Project
}

\author{
Rossella Bovolenta ${ }^{(凶)}$, Roberto Passalacqua, Bianca Federici, \\ and Domenico Sguerso \\ Department of Civil, Chemical and Environmental Engineering, \\ University of Genoa, via Montallegro 1, 16145 Genoa, Italy \\ rossella.bovolenta@unige.it
}

\begin{abstract}
The authors refer in this paper some of the analyses already done and the planned activities in developing the AD-VITAM Project (InterReg V-A France - Italy - E.U. ALCOTRA), which aims to assess the most suitable techniques to obtain a reliable forecasting of rain-induced landslides, in order to enhance the territorial resilience when subject to such a risk. The authors refers about the procedure called LAMP (Landslides Monitoring and Predicting), consisting in an Integrated Hydrological/Geotechnical numerical model (IHG) fed by site-specific installed sensor-network, to help in the start-up calibration of some of the relevant parameters used by the model. The tuned-up simulation models is used to assess the landslide susceptibility to measured/predicted rainfall histories. The implementation of the numerical geotechnical/hydrological models on a GIS platform with regard to some of the selected sites, and the preliminary tests performed on the sensors to be installed on-site in order to monitor the real-time response to rainfalls are briefly described. Thanks to the effective cooperation with the local technicians and the project partners, the final achievements of AD-VITAM could furnish a real support to a better protection of both the natural and the urbanized environments, allowing site-specific warnings and a better hydro-geological risk management capacity.
\end{abstract}

Keywords: Landslide · Rainfall · Sensors · Stability · Modelling · Susceptibility

\section{Introduction}

AD-VITAM (“Analisi Della Vulnerabilità dei Territori Alpini Mediterranei ai Rischi Naturali") is a project funded by INTERREG V-A France - Italy - E.U. ALCOTRA program 2014-2020, started on May 2017 and running up to April 2020. The project leader is the Centre National de la Recherche scientifique (CNRS - F), partners are the Bureau de Recherches Géologiques et Minières (BRGM - F), the Laboratoire Géoazur - Université Nice Sophia Antipolis (F), the Regional Agency for the Protection of the Ligurian Environment (ARPAL - I), the Piedmont Region (I), the Foundation 
"Montagna Sicura" (I), the Union of the Municipalities of Argentina-Armea Valleys (I) and the DICCA Dept. of the University of Genoa (I).

It aims to improve the resilience of territories in the face of the risk of landslides induced by rain, bringing together the skills of research groups with those of local actors. Through the study of historical phenomena and equipping representative sites of the territory with sensors, different models in GIS environment will be improved and applied to evaluate the susceptibility to slide, to define landslide activation threshold and to elaborate dynamic warning maps based on precipitation frequencies. The forecasting models are going to help the operational management by the technicians in charge of land use planning and civil protection, both at the level of the central authorities and of the local communities exposed to the problem of landslide management.

In particular, within the WPs 4.1 and 4.2 of AD-VITAM project, two models are object of application and comparison in the next future: ALICE (Assessment of Landslides Induced by Climatic Events) of BRGM and LAMP (Landslides Monitoring and Predicting), the latter from the authors, both implemented on GIS platforms.

ALICE is a physically based model, designed to be applied to a single site or phenomenon. It is based on the global limit equilibrium method with a $2.5 \mathrm{D}$ approach. It allows to calculate the safety factors on the surface of maximum slope, processing contiguous sections of the area under study. The geotechnical parameters are distributed over the entire area by probabilistic distributions, thus obtaining a probabilistic distribution of different breaking surfaces. ALICE uses the GARDENIA hydrological model to calculate the actual groundwater level starting from a single rainfall value over the entire area under consideration (Thiery et al. 2017).

LAMP is more than a model, it is a system for the monitoring and for the analysis/forecasting of rainfall triggered landslide susceptibility. LAMP is composed by an Integrated Hydrological/Geotechnical numerical (hereinafter referred to as IHG) model fed by site-specific installed sensor-network, to help in the start-up calibration of some of the relevant parameters used by the model (Federici et al. 2014; Bovolenta et al. 2016; Passalacqua et al. 2016). IHG is a physically based model, like ALICE model, but that integrates both hydrological and geotechnical modelling. It is designed to be applied to a single site or landslide phenomenon, fed by a rain history that varies in space and time. The calculation procedure and the sensor typology are detailed in the following section.

In literature many other models have been proposed for rainfall-induced landslide analyses, applying geotechnical models and using the safety factor formulation. The soil is usually assumed isotropic and homogeneous, accounting for the horizontal heterogeneity varying the parameters from cell to cell (e.g. Iverson 2000; Baum et al. 2002; Montrasio and Valentino 2008). From the hydrological point of view, the steady state or physically based models of the hill slope hydrology are usually adopted to simulate the processes involved (e.g. Montgomery and Dietrich 1994; Wu and Sidle 1995; Qiu et al. 2007; Lu and Godt 2008; Baum et al. 2010). The computational effort is usually considerable, hence such models are poorly suited to analyse wide areas. Moreover, the most common two-dimensional limit equilibrium stability approaches are often unsuited at the overall watershed scale, or on wide areas, where the kinematic phenomena have a pronounced three-dimensional character. 
The proposed IHG model has the ambition to overcome these limits by means of a simplified model, in order to be computationally light, hence applicable in near real time to model the response of a landslide to occurring, or forecasted, rainfalls.

Moreover, low cost and spatially distributed soil moisture sensors will be used to calibrate the infiltration rates into the IHG model, together with rain gauges or weather radars to measure rainfalls, as well as air temperature sensors to evaluate evapotranspiration. Furthermore, GNSS (Global Navigation Satellite Systems) receivers will be also installed on the ground to check the model results.

The authors will here refer some of the analyses already done and the planned activities in the ongoing developing. In particular, the application of the IHG model to some of the sites chosen collectively by the project Partners in France and Italy, and the calibration procedure of soil water content sensors are described in the following. LAMP application in real-time will be tested in the near future within AD-VITAM project.

\section{LAMP (Landslide Monitoring and Predicting)}

LAMP identifies susceptibility of landslide triggered by rainfall by means of a hydrogeotechnical model (Passalacqua et al. 2015, 2016) fed and calibrated by a site-specific sensor network (Bovolenta et al. 2016) and on the basis of the measured or predicted rainfall histories. It is applied to a single site or landslide phenomenon at a time, typically at scale 1:5000 (Passalacqua and Bovolenta 2015).

The LAMP final products will be maps of landslide susceptibility in the occurrence of a rainfall history and maps forecasting the susceptibility evolution on the expected short-term rain. The maps will be rendered in raster format, choosing a semaphore color dithering scale, thus resulting of great immediacy even for users who are not expert in GIS.

The knowledge of the areas with high susceptibility to instability could activate alarms before the phenomenon manifests itself.

In the following paragraphs the IHG model and the sensor network will be briefly illustrated.

\subsection{The IHG Model for Landslide Susceptibility Estimation}

The IHG model is a physically based model, which integrates both hydrological and geotechnical modeling, as illustrated in Fig. 1. The model, fed by sensor data, could analyze, in real time, the propensity to collapse of different portions of the territory, by establishing a cause-and-effect relationship between site-specific rainfalls and the eventual occurrence of localized landslides.

The site modeling is completely 3D, both geometrically and in terms of geotechnical and hydrological parameters, that are spatially distributed through appropriate interpolations and extrapolations of local data derived by on-site investigations. Data related to the ground water conditions (by few piezometers), stratigraphy, soil physicalmechanical parameters and permeability are necessary and can be defined una tantum by usual field investigations. 


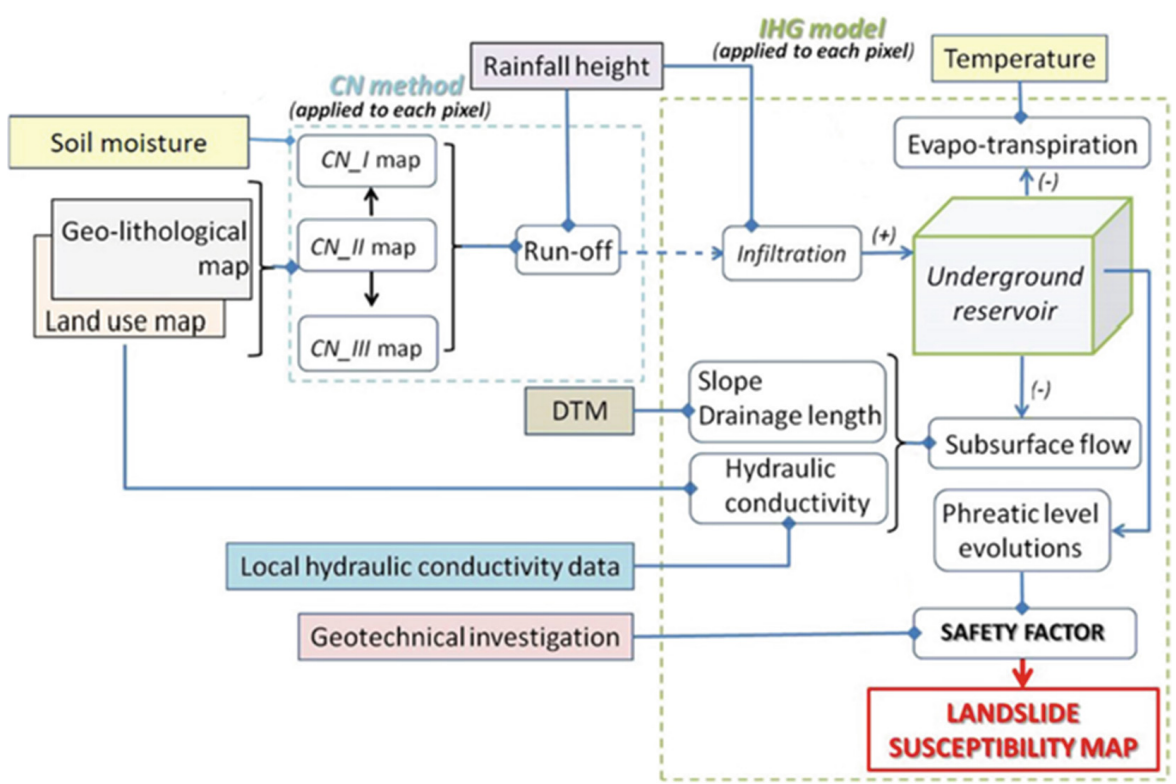

Fig. 1. Scheme of the Integrated Hydrological-Geotechnical modeling (IHG) implemented in LAMP.

The procedure determines first the groundwater variations, depending on the rainfall history examined. For this purpose, the modified Curve Number method (SCS 1972-1975) is used to calculate the amount of rain that infiltrates, depending on the land use and the soil wetting condition based on the previous three days' rain histories. Subsequently, each discretization cell is considered as a reservoir in which infiltrated rain water enters. The water exits from this reservoir by underground drainage and evapotranspiration. Once the water table resulting from the occurred rain has been determined, the model performs a stability analysis in effective stresses onto each one of the individual discretization cells. The failure surface (evaluated for different depths up to the stable substrate) and the water table are assumed to be parallel to the ground (pertinent to each cell). The interaction forces between the cells and the edge effects are neglected (this will be improved as well as the hydraulic exchanges among cells). This methodology may recall the method by Skempton and Delory (1957) since it is assumed that the failure surface is an inclined plane approximately parallel to the slope and the geomechanical properties of the soil and effective pressures are constant along planes parallel to the ground. Differently from Skempton and Delory (1957), the safety factor is calculated with reference to each pixel of the studied area that may differ from the adjacent ones about the geometrical and physical-mechanical characteristics, variable even along depth. Hence the safety factor is calculated with reference to an element and is not extended to the entire slope, as instead happens in the indefinite slope studied by Skempton and Delory (1957). 
The final result of the IHG model is a map of landslide susceptibility, distributed over the entire analysed area, based on the spatial variation of the safety coefficients due to the occurring, or assumed, rainfalls.

\subsection{The Sensor Network}

As mentioned above, LAMP proposes the use of a dense, low-cost and self-sufficient network of sensors to be disseminated on site, whose measures shall be sent by a Wireless Sensor Network to the IHG model (Bovolenta et al. 2016). The sensor network should mainly monitor the local infiltration conditions, but also the surface displacements.

In particular, the data needed for the analyses are:

- continuous measurement of rain histories, by rain gauges or meteorological radar;

- continuous air temperature measurements;

- continuous measurements of the soil moisture contents.

Shallow and deep displacement measurements, usually gathered by topographic and inclinometer methods, are not strictly necessary but, if available, are extremely useful to reckon the slope response. The low-cost GNSS receivers, which will be adopted, use a single-frequency to take advantage of the precision of phase measurements, and are enabled to send observations to a server to allow a post-processing positioning from sessions of several hours, in order to achieve an optimal accuracy.

Hereinafter, the authors briefly illustrate the soil moisture sensors that will be adopted for the landslide monitoring in AD-VITAM project, necessary to evaluate the shallow infiltration conditions of the slope. Since much of the Italian territory is subject to landslides, the possibility of using low-cost sensors for monitoring widespread areas is particularly appealing, provided that these sensors guarantee satisfactory accuracy and precision and good compatibility with the acquisition systems. Low cost sensors may be distributed with an acceptable high spatial density. Moreover, they are generally easily relocatable, autonomous and remotely controllable. It is also necessary to choose suitable sensors for environmental monitoring, not sensitive to the effects of temperature, salinity, soil texture, etc. The soil moisture capacitance probes appear to be particularly suitable for monitoring landslide areas. WaterScout-SM100 probes were appropriately tested and calibrated, before of the installation in the sites to be monitored in Italy and France. The experimental activities are currently in progress:

- in laboratory: by calibrating a soil moisture capacitance probe, in sandy soils and sandy soils with clay;

- in a test field: by a comparative analysis of water content measurements in the soil carried out by capacitive WaterScout SM100 probes by Spectrum Technologies Inc. - USA (two vertical instrumented with 4 aligned sensors, according to different provisions) and one Drill \& Drop by Sentek Technologies - AUS (with multiple sensors set at intervals of $10 \mathrm{~cm}$ along the total length of the probe: $90 \mathrm{~cm}$ ).

These tests will allow us to calibrate the probes and optimize their layout and installation on site, verifying that the entire monitoring system is fully operational, easily installable and transmits correctly the collected data over a GSM link. The 
sensors installed on site will be self-sufficient for electrical power supply by solar panels and backup batteries. They will be connected by a wireless network composed by:

- many nodes, each one provided with a thermometer, 4 low-cost sensors of soil moisture content (arranged along a vertical, circa in the first meter depth from the soil surface) hardwired to a collecting 'pup', this equipped with a WiFi modem;

- one "gateway" receiving data from all the nodes pups and sending them to a remote server, by a GSM link.

\section{Sites Under Study}

In the AD-VITAM Project, LAMP will be applied to French and Italian sites, following the subsequent operational phases:

1. data collection for the characterization and hydrological-geotechnical analysis of the site;

2. realization on a GIS platform of the 3D model of the site (DTM, bedrock, water table) and its characterization with the soil physical-mechanical parameters, if necessary discretized in different layers;

3. preliminary analyses based on available historical data;

4. comparison among different methodologies:

- analysis in GIS environment by means of the IHG model (3D)

- global limit equilibrium methods (both 2D and 3D)

- FEM numerical analysis (both 2D and 3D)

- ALICE BRGM's model;

5. in situ validation;

6. planning and installation of sensors network;

7. IHG application based on the acquired monitoring data.

In the following, two of the chosen sites are briefly illustrated.

\subsection{Mendatica (Italy)}

Mendatica is a small Italian village in the Liguria Region, situated at $800 \mathrm{~m}$ a.s.1. in the Arroscia River Valley. This hamlet is particularly susceptible to slope instability, because it is located in part in an active landslide zone (about 10 hectares), in part in a dormant zone (about 250 hectares in total). A lack of geological information of the subsoil has led to several cognitive surveys starting from 2005. In autumn 2005 a surface geologic survey was performed, in order to evaluate the landslide perimeter and depth. Then, cracks on existing buildings were monitored. In the second half of 2006 geotechnical investigations have been added, to support a proper definition of the hydro-geological model and to design further countermeasures. In particular, 13 boreholes were performed in different areas of the village, to obtain precise stratigraphic data and assess the local depth of the bedrock (variable between 15 and 40 meters). Moreover, some soil samples have been subjected to geotechnical laboratory 
analyses. In addition to the vertical boreholes, three down-holes, one seismic refraction and four Lefranc tests were performed too. An in situ monitoring system, with vertical holes, inclinometers and piezometers started in 2007 and it is still active. In the following years, after some reactivations caused by severe rainfall events, new instrumentations were installed: piezometers, inclinometers, crack-meters and a new rain gauge (installed in January 2015). These were installed both to replace the out of order ones and in addition to the still working instrumentations. Geological reports confirm that the reactivations are mainly triggered by the rainfall events. The past studies revealed an extremely heterogeneous composition of the soil deposit and a very complex hydrogeology correlated to a significant variation of the soil permeability. In order to control and limit the groundwater presence, several countermeasures have been done. Regulation of the small streams, reconditioning of aqueduct and sewer systems, soil drainage (by means of vertical, sub-horizontal and electro-pneumatic drains) were done, to capture and convoy exceptional rainfalls and groundwater flows at near collectors; finally, a top draining trench $(6 \mathrm{~m}$ deep) to avoid water infiltration in the downhill landslide was realized.

Collected all the available data, the 3D model of the site at $5 \mathrm{~m}$ resolution was realized on GIS (Fig. 2). The soil was described by three different layers, of different features, in order to better reproduce the observed groundwater oscillation.
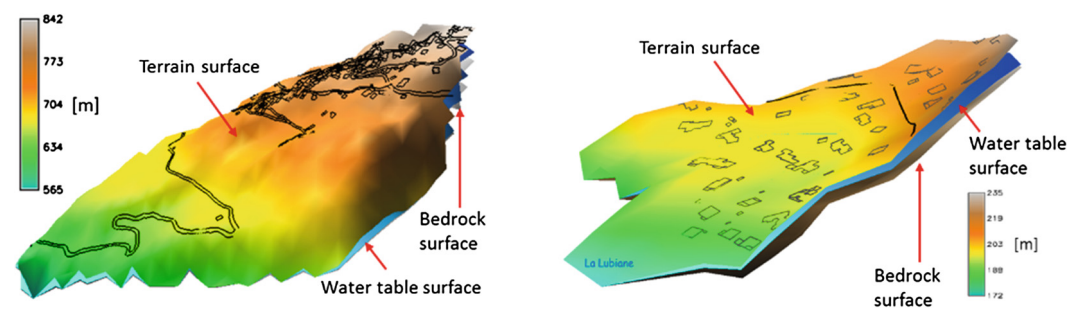

Fig. 2. 3D model at $5 \mathrm{~m}$ resolution in GIS platform: Mendatica site (Italy) on the left and Vence site (France) on the right.

Preliminary analyses based on historical data have been performed by using the IHG model. The model parameters were calibrated so to allow locally a good correspondence between the observed groundwater oscillation during several significative rainfall events and the modelled one. Hence susceptibility maps after a rainfall event were produced and compared with the ones relative to pre-event condition, highlighting the areas that become unstable due to the event itself (Fig. 3). Figure 3 shows an example of the resulting IHG map and also the photographs of failures (denoted by the letter A) that occurred in areas found critical by the model. Instead the photo denoted by the letter B shows an intervention realized in an area judged by the modeling as unstable. Moreover, the results have been compared with classical global limit equilibrium methods and FEM numerical analyses, identifying corresponding critical zones, also confirmed by in situ validation.

Recently, the influence of the buildings has been modelled, applying a load to each "built pixel", which is function of the material (reinforced concrete, masonry, stone), 


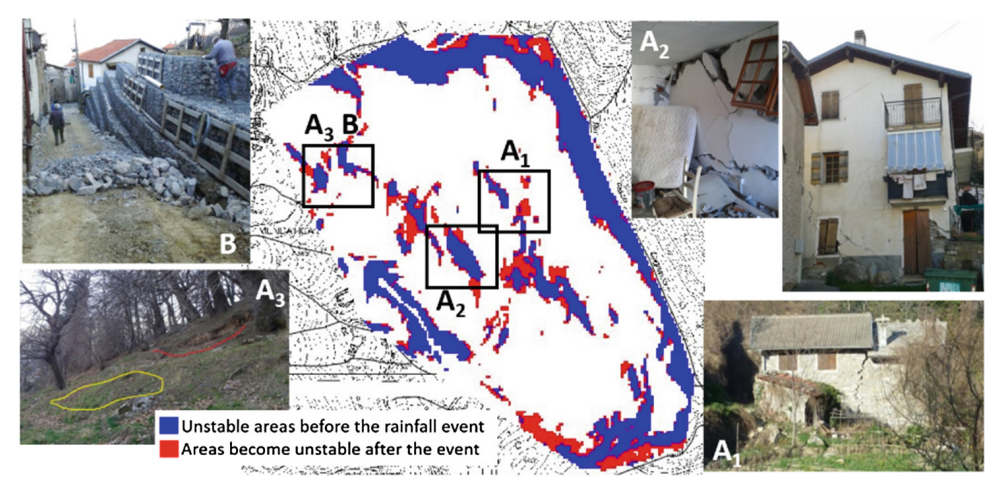

Fig. 3. Mendatica site (Italy): IHG resulting map identifying unstable area before and after the rainfall event (07/01/2008-19/01/2008) and localization of some instabilities (denoted by A) or countermeasures on site (denoted by B).

number of floors (generally less than three floors). The influence of such improvement will be analysed and shown in the near future. The sensor network will be posed very soon, furnishing the monitoring data to the IHG application, as prescribed by LAMP.

\subsection{Vence (France)}

Vence is a small French village in the territory of the Maritime Alps. The landslide phenomenon at the Prat de Julian site is one of the most important movements on the territory of the PACA Region. This ancient landslide has undergone numerous reactivations over time as evidenced by the bearing morphology at the foot of the slope that deviated the course of the Lubiane water stream. The volume is approximately equal to $800000 \mathrm{~m}^{3}$. The slide plan dimensions involved are $350 \mathrm{~m}$ in length and $250 \mathrm{~m}$ in width. The direction of the movement is South-South West, with a medium-low surface grading $\left(12^{\circ}-14^{\circ}\right)$. The poor geotechnical characteristics of the $15 \mathrm{~m}$ thick sandyclayey blanket, the erosive action of the Lubiane stream and the complicated circulation of water inside of the top soil render critical the site stability. In the presence of intense rainy phenomena, immediate reactivations occur. The site model was defined using the results of 25 boreholes, laboratory tests, inclinometer and piezometric measurements. The 3D model of the site of Prat de Julian is represented in Fig. 2.

Preliminary analyses based on the historical data provided by the French Partners has been performed. An example of the resulting map is represented in Fig. 4, pertinent to one of the rainfall events which have been studied, from 18/12/2010 to 28/12/2010. In Fig. 4 the images denoted by the letter A show buildings that have been demolished due to the instability actually occurred. Within zone B, no evidence of failure or building demolitions were detected. However, the model IHG identifies this area as unstable due to groundwater oscillations. Actually, this area (area B in Fig. 4) is classified as unstable in the French plans and no buildings are present today. 


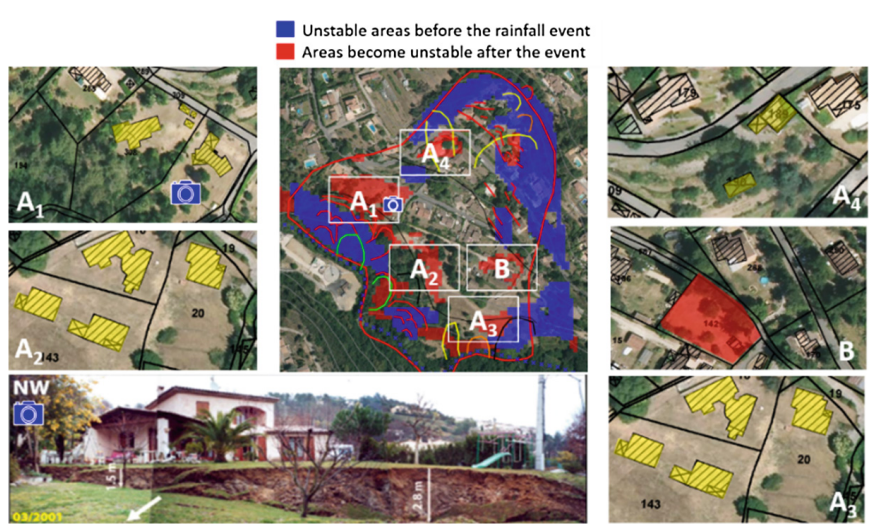

Fig. 4. Vence (France): IHG resulting map identifying unstable area before and after the rainfall event (18/12/2010-28/12/2010) and localization of some buildings that were demolished (denoted by A) or where constructions were not allowed (denoted by B).

\section{Conclusions}

In this paper the authors refer some of the analyses and the planned activities in developing the AD-VITAM Project (InterReg V-A France - Italy - E.U. ALCOTRA).

More specifically, the authors illustrate the LAMP project. LAMP (LAndslide Monitoring and Predicting) is a system for the monitoring and for the analysis/forecasting of rainfall triggered landslide susceptibility. It proposes the use of a dense, low-cost and self-sufficient network of sensors to be disseminated on site, whose measures are sent to an Integrated Hydrological/Geotechnical model (Bovolenta et al. 2016), able to establish a cause-and-effect relationship between rainfall and occurrence of the landslide.

The LAMP procedure herein described has yet shown, being used in its preceding applications, to be both reliable and fast; in fact, a site deposit discretized by circa a million of $3 \mathrm{D}$ block unit-cells $(5 \mathrm{~m}$ wide $\times 5 \mathrm{~m}$ length $\times 1 \mathrm{~m} \mathrm{depth}$ ), being subjected to a 3 days rainfall history, accomplished the overall analyses within $5 \div 6$ min on a standard computer. With respect to other competing 3D approaches (FEM and Limit Equilibrium based), LAMP allows a much finer site 'tessellation' and runs much faster; thus and in conclusion, it represents a very useful and affordable tool to assess and predict the hydro-geological risk. LAMP may furnish a real support to a better protection of both the natural and the urbanized environments, allowing site-specific warnings and a better hydro-geological risk management capacity. Moreover, the LAMP implementation may be a valid contribution to the urban and environmental planning activities.

Acknowledgements. The activities presented in this paper are part of the AD-VITAM Project, funded by the INTERREG V-A FRANCE-ITALIE ALCOTRA 2014-2020. The authors wish also thank all of the Project Partners for their fruitful collaboration. 


\section{References}

Baum RL, Savage WZ, Godt JW (2002) TRIGRS -A Fortran program for transient rainfall infiltration and grid-based regional slope-stability analysis. USGS Open-File Report 02-424

Baum RL, Godt JW, Savage WZ (2010) Estimating the timing and location of shallow rainfallinduced landslides using a model for transient, unsaturated infiltration. J Geophys Res Earth Surf 115 (F3)

Bovolenta R, Passalacqua R, Federici B, Sguerso D (2016) LAMP Landslide Monitoring and Predicting for the analysis of landslide susceptibility triggered by rainfall events. 12th International Symposium on Landslides (ISL2016) 12th-19th June in Naples, Italy, vol. 2, pp 517-522

Federici B, Bovolenta R, Passalacqua R (2014) From rainfall to slope instability: an automatic GIS procedure for susceptibility analyses over wide areas, Geomatics, Natural Hazards \& Risk. The Role of Geomatics in Hydrogeological Risk 6(5-7), 2015. ISSN: 1947-5713. https://doi.org/10.1080/19475705.2013.877087

Iverson RM (2000) Landslide triggering by rain infiltration. Water Resour Res 36:1897-1910

Lu N, Godt J (2008) Infinite slope stability under steady unsaturated seepage conditions. Water Resour Res 44:W11404. https://doi.org/10.1029/2008WR006976

Montgomery DR, Dietrich WE (1994) A physically based model for the topographic control on shallow landsliding. Water Resour Res 30(4):1153-1171

Montrasio L, Valentino R (2008) A model for triggering mechanisms of shallow landslides. Nat Hazards Earth Syst Sci 8:1149-1159. https://doi.org/10.5194/nhess-8-1149-2008

Passalacqua R, Bovolenta R (2015) Landslides' susceptibility on large surfaces triggered by rain histories, Proc. of the XVIth European Conference on Soil Mechanics \& Geotechnical Engineering (ECSMGE), Edinburgh (UK) 13-17, September 2015, ICE Publishing 2015, ISBN 978-0-7277-6067-8. https://doi.org/10.1680/ecsmge.60678, pp 1831-1836

Passalacqua R, Bovolenta R, Federici B, Balestrero D (2016) A physical model to assess landslide susceptibility on large areas: recent developments and next improvements. Italian Conference of Researchers in Geotechnical Engineering (CNRIG), Bologna, 22-23, September 2016, Procedia Engineering 158, ISSN: 1877-7058. https://doi.org/10.1016/j. proeng.2016.08.477, pp 487-492

Passalacqua R, Bovolenta R, Federici B (2015) An integrated hydrological-geotechnical model in GIS for the analysis and prediction of large-scale landslides triggered by rainfall events. Engineering Geology for Society and Territory - Volume 2: Landslide Processes 1 January 2015, pp 1799-1803

Qiu C, Esaki T, Xie M, Mitani Y, Wang C (2007) Spatio-temporal estimation of shallow landslide hazard triggered by rainfall using a three-dimensional model. Environ Geol 52:1569-1579

SCS - Soil Conservation Service (1972) Hydrology. In: National engineering handbook section 4, U.S. Dept. of Agriculture, Washington, D.C., USA

SCS - Soil Conservation Service (1975) Urban hydrology for small watersheds. Tech. Rel. No. 55, U.S. Dept. of Agriculture, Washington, D.C., USA

Skempton AW, Delory FA (1957) Stability of natural slopes in London Clay. In Proc. 4th Int. Conf. Soil Mech. 2:378-381

Thiery Y, Vandromme R, Maquaire O, Bernardie S (2017) Landslide susceptibility assessment by EPBM (Expert Physically Based Model): Strategy of calibration in complex environment. In: Mikos M, Tiwari B, Yin Y, Sassa K (eds) Advancing culture of living with landslides. WLF 2017. Springer, Cham

Wu W, Sidle RC (1995) A distributed slope stability model for steep forested basins. Water Resour Res 31(8):2097-2110 